\title{
Integração ensino-serviço-comunidade na perspectiva da reorientação da formação em saúde
}

\author{
Carine Vendruscolo \\ Enfermeira. Doutora em Enfermagem. Professora Adjunta do Departamento de Enfermagem da Universidade \\ do Estado de Santa Catarina (UDESC) \\ $\square$ carine.vendruscolo@udesc.br \\ Maira Tellechea da Silva \\ Enfermeira. Professora da Área de Ciências da Saúde da Unochapecó \\ Maria Elisabeth Kleba da Silva \\ Enfermeira. Professora da Área de Ciências da Saúde da Unochapecó
}

Recebido em 27 de setembro de 2017

Aceito em 23 de novembro de 2017

\section{Resumo:}

A proposta da integração ensino-serviço-comunidade se orienta pelos pressupostos conceituais que incorporam o processo de educação à transformação social, com base nas necessidades dos sujeitos, no âmbito do seu contexto histórico e social. O estudo apresenta como objetivo identificar resultados produzidos pela implementação dos programas interministeriais (Ministérios da Saúde e Educação) Pró-Saúde e Pet-Saúde na integração ensino-serviço, de acordo com o olhar de profissionais e gestores. Estudo de caso realizado no município de Chapecó/SC, cujos dados foram coletados por meio de grupos focais. A integração ensino-serviço está, em grande medida, presente no pensamento e no trabalho dos profissionais e dos gestores, os quais se compreendem como (co)responsáveis no processo de reorientação da formação. Todavia, a maior parte dos atores refere dificuldades para participar das ações e demandas da Instituição de Ensino, seja pelo excesso de trabalho, seja por falta de estímulos ou ainda por desconhecimento do que envolve o processo de formação na saúde.

Palavras-chave: Ensino, Atenção Primária à Saúde, Sistema Único de Saúde, Integração docente assistencial.

\section{Integration service learning community in the perspective of feedback of vocational health training}

\begin{abstract}
:
The integration service is guided by the conceptual assumptions that incorporate the process of education for social transformation, based on the real needs of individuals, as part of its historical and social context. This study has the objective to identify results produced by the implementation of the interministerial programs (Ministries of Health and Education), Pró-Saúde and Pet-Saúd in the integration of education and health services, according to the look of professionals and managers. Case study in Chapecó/SC, whose data were collected through focus groups. The integration service learning is largely present in the thought and work of professionals and managers, who understand how it is (co) responsible in the training process of reorientation. However, most of the actors referred difficulties to participate in the actions and demands of education institution, either by overwork, either for lack of stimuli or by ignorance of what involves the process of training in health.

Keywords: Teaching, Primary Health Care, Unified Health System, Teaching assistance integration.
\end{abstract}




\title{
Integración enseña-servicio-comunidad en la perspectiva de la reorientación de la formación en salud
}

\begin{abstract}
Resumen:
La propuesta de la integración enseñanza-servicio-comunidad se orienta por los presupuestos conceptuales que incorporan el proceso de educación a la transformación social, con base en las necesidades de los sujetos, en el marco de su contexto histórico y social. El estudio presenta como objetivo identificar resultados producidos por la implementación de los programas interministeriales (Ministerios de Salud y Educación) Pró-Saúde y Pet-Saúde en la integración enseñanza-servicio, de acuerdo con la mirada de profesionales y gestores. Estudio de caso realizado en el municipio de Chapecó / SC, cuyos datos fueron recolectados por medio de grupos focales. La integración enseñanza-servicio está, en gran medida, presente en el pensamiento y en el trabajo de los profesionales y de los gestores, los cuales se entienden como (co) responsables en el proceso de reorientación de la formación. Sin embargo, la mayoría de los actores mencionan dificultades para participar en las acciones y demandas de la Institución de Enseñanza, sea por el exceso de trabajo, sea por falta de estímulos o aún por desconocimiento de lo que implica el proceso de formación en la salud.
\end{abstract}

Palabras clave: Enseñanza, Atención Primaria a la Salud, Sistema Único de Salud, Integración docente asistencial.

\section{INTRODUÇÃo}

Em 2003, o Ministério da Saúde (MS) instituiu dispositivos importantes de articulação entre a educação e o trabalho em saúde. A partir de diálogos com o Ministério da Educação, desenvolveu parcerias em programas para fortalecer o processo de formação e desenvolvimento profissional, com vistas a qualificação da Atenção Básica (AB). Entre as ações relacionadas à educação superior para melhoria dos cursos de graduação, destacamse: o Programa Nacional de Reorientação da Formação Profissional em Saúde (Pró-Saúde) e o Programa de Educação pelo Trabalho para a Saúde (PET-Saúde).

O Pró-Saúde, lançado em 2005 com o objetivo de promover transformações no ensino na saúde, teve como foco cursos de graduação em enfermagem, medicina e odontologia, três categorias que integram as equipes da Estratégia Saúde da Família (ESF), dispositivo prioritário para a reorientação do modelo de AB no Brasil. Em 2008, um novo edital inclui os demais cursos da área da saúde, acompanhando a iniciativa do MS de instituição dos Núcleos de Apoio à Saúde da Família (NASF). Um terceiro edital, lançado em 2011, articula a organização de projetos de reorientação da formação à criação das Redes de Atenção à Saúde (RAS), destacando ainda o papel da $\mathrm{AB}$ como coordenadora nas linhas de cuidado em saúde. O Pró-Saúde propõe que a criação de modelos de reorientação apoia a construção de um novo panorama na formação profissional, com vistas ao ensino integrado 
com o serviço público, tendo como base as reais necessidades da população e dos trabalhadores da saúde (BRASIL, 2007a). Por sua vez, lançado em editais anuais de 2008 a 2013, o PET-Saúde tem como pressuposto a educação pelo trabalho, disponibilizando bolsas para tutores (docentes universitários), preceptores (profissionais dos serviços) e estudantes de graduação da área da saúde (BRASIL, 2010).

Esses programas têm como orientação comum a proposta de integração ensinoserviço-comunidade no processo de formação, destacando os cenários de prática como lócus singular para a reflexão sobre a real condição da produção de cuidados e a necessidade de transformação do atual modelo de atenção, centralizado no profissional e nas técnicas. Essa interação consiste no trabalho coletivo, pactuado e integrado entre docentes e discentes dos cursos de formação, trabalhadores, gestores e usuários dos serviços (BRASIL, 2007b; VENDRUSCOLO; PRADO; KLEBA, 2016).

A integração ensino-serviço-comunidade está ancorada aos pressupostos conceituais que incorporam o processo de educação à transformação social, com base na análise das necessidades reais dos sujeitos, no âmbito do seu contexto histórico e social. Freire (2001) defende a educação como uma possibilidade em que educando e educador atuem de forma compartilhada, como sujeitos de sua prática, e que esta deve ser criada e recriada por meio da ação-reflexão-ação sobre o cotidiano. Schimidt (2008) refere-se aos espaços de ação e de reflexão como mundos em transformação: o mundo do trabalho e o mundo da educação em saúde. Quando em intersecção, esses mundos se transmutam em algo novo, uma espécie de imagem objetivo, em que é possível instituir o diálogo com outras realidades, originando novos fatos.

Orientado por esses pressupostos e atendendo as Diretrizes Curriculares Nacionais (DCNs) (BRASIL, 2001), o Curso de Enfermagem da Universidade Comunitária da Região de Chapecó (Unochapecó) aprovou seu projeto de reorientação da formação no edital do PróSaúde 1, o que fomentou maior engajamento de atores internos e externos ao processo. Em 2008, outros cursos aprovaram a proposta integrada de reorientação da formação, no PróSaúde 2, envolvendo gestores e profissionais da Secretaria da Saúde (Sesau) do município, além de professores e estudantes. A partir de 2009, essa parceria se fortaleceu na aprovação de projetos no PET-Saúde da Família, Vigilância à Saúde, Saúde Mental e Redes de Atenção à Saúde. Em 2012 foi aprovado, incluindo a participação da Gerência da Saúde (Gersa) de 
Chapecó o Pró-PET-Saúde, estratégia do MS para fortalecer a adesão dos profissionais de saúde no processo de reorientação do ensino de graduação.

O processo de articulação fortalecido por meio dessas parcerias favoreceu a inserção dos estudantes nos cenários dos serviços de saúde para o desenvolvimento de atividades teórico-práticas, com destaque aos estágios. De acordo com a Lei 11.788/08, o estágio se caracteriza como "ato educativo escolar supervisionado, desenvolvido no ambiente de trabalho, que visa a preparação para o trabalho produtivo de educandos que estejam frequentando o ensino regular em instituições de educação superior" (BRASIL, 2008, p. 1).

Este artigo apresenta resultados de uma pesquisa desenvolvida pela Unochapecó, tendo como parceiros a Sesau e a Gersa de Chapecó, que buscou identificar repercussões da implementação do Pró-Saúde e PET-Saúde na integração entre o ensino e o serviço, de acordo com o olhar dos atores envolvidos no processo.

\section{METODOLOGIA}

Estudo de caso (YIN, 2010), tendo como recorte um dos projetos do Pró-Saúde desenvolvidos em parceria entre Instituição de Ensino Superior (IES) e Sesau de Chapecó, Santa Catarina: o projeto Vivências Interdisciplinares e Multiprofissionais (VIM). A escolha desse projeto deu-se por envolver os dez cursos da saúde oferecidos pela Unochapecó (Ciências Biológicas, Educação Física, Enfermagem, Farmácia, Fisioterapia, Medicina, Nutrição, Odontologia, Psicologia e Serviço Social); ter inserção no ensino e na extensão, fortalecendo a integração ensino-serviço, conforme preconiza o Pró-Saúde. O VIM é desenvolvido por meio de encontros tutoriais na IES, observação no território adstrito nas 27 unidades de saúde do município e socialização da experiência entre envolvidos. Esse projeto inclui em torno de trezentos estudantes, trinta tutores (professores vinculados aos componentes curriculares integrados na proposta e profissionais da rede de $A B$ ) e trinta acolhedores (trabalhadores das unidades de saúde, nas quais a observação é realizada). Objetiva promover, junto aos estudantes, reflexões sobre o processo de implementação do Sistema Único de Saúde (SUS) nos territórios da AB, bem como sobre o papel dos diferentes atores da equipe multiprofissional nesse processo. Isso ocorre mediante a possibilidade de 
inserção precoce dos estudantes em cenários da prática, observação do cotidiano das atividades interdisciplinares dos profissionais de saúde dos serviços e posterior reflexão sobre os mesmos, com a mediação dos tutores.

Foram coletados depoimentos de profissionais da $A B$ e gestores da Sesau. A definição dos participantes levou em conta os seguintes critérios: a) ser trabalhador atuante na rede municipal de saúde, envolvido com regularidade nos projetos do Pró e PET-Saúde nos últimos três anos, ou b) exercer cargo de gestão na estrutura central da Sesau, pelo período mínimo de um ano nos últimos três anos. Sete profissionais e seis gestores, respectivamente, participaram, em agosto de 2012, em dois grupos focais (BARDIN, 2011) realizados separadamente com cada segmento.

As sessões foram conduzidas por uma entrevistadora e uma relatora, professoras do grupo de pesquisadores, tendo como tempo médio de debate duas horas. Os diálogos nos grupos foram iniciados mediante perguntas norteadoras, enunciadas pela entrevistadora, sendo gravados e, posteriormente, transcritos e validados pelos participantes. As informações foram tratadas mediante Análise Temática (BARDIN, 2011) à luz dos marcos legais do SUS; das DCN; dos pressupostos do Pró e PET-Saúde e de outras ações estruturantes interministeriais de reorientação da formação em saúde; além de obras de autores que estudam a temática.

Foram respeitados os aspectos éticos requeridos para pesquisas com seres humanos, sendo o projeto aprovado pelo Comitê de Ética em Pesquisa da Unochapecó, sob protocolo de $\mathrm{N}^{\circ}$ 202/2010, obtendo-se dos participantes Termos de Consentimento Livre e Esclarecido assinados. As identidades dos participantes foram resguardadas, sendo as falas identificadas por meio do segmento que os autores representam seguido do número relativo a ordem de inserção no respectivo grupo focal.

\section{RESULTADOS}

Em relação ao perfil dos participantes, destaca-se a maioria do sexo feminino: nove mulheres e quatro homens. As profissões representadas incluíram cinco cirurgiões 
dentistas, três médicos, duas enfermeiras, uma psicóloga, uma assistente social e uma fisioterapeuta.

Os diálogos entre pesquisadores, profissionais e gestores resultaram nas seguintes categorias temáticas (CT), em relação à integração ensino-serviço: Mundos entrelaçados: participação dos profissionais nas atividades acadêmicas e dos estudantes no cotidiano da equipe de saúde; A teoria e a práxis no contexto da reorientação da formação e do modelo de atenção; Analogias entre os mundos do trabalho e do ensino. O quadro 1 ilustra o panorama geral dos resultados, por meio de uma listagem das principais CT e suas características.

Quadro 1 - Categorias e respectivas características que sintetizam a percepção de profissionais e gestores da saúde sobre a integração ensino-serviço.

\begin{tabular}{|c|c|}
\hline \multicolumn{2}{|r|}{ SÍNTESE DOS RESULTADOS } \\
\hline $\begin{array}{l}\text { Categorias } \\
\text { Temáticas (CT) }\end{array}$ & Características \\
\hline $\begin{array}{l}\text { CT1 }- \text { Mundos } \\
\text { entrelaçados: participação } \\
\text { dos profissionais nas } \\
\text { atividades acadêmicas e dos } \\
\text { estudantes no cotidiano da } \\
\text { equipe de saúde }\end{array}$ & $\begin{array}{l}\text { Profissionais alheios à passagem dos estudantes, } \\
\text { imersos em sua prática laboral. } \\
\text { Envolvimento espontâneo ou a partir de } \\
\text { incentivos financeiros aos profissionais pode influenciar } \\
\text { no maior grau de participação. } \\
\text { A Inserção do estudante implica na educação } \\
\text { permanente dos profissionais. }\end{array}$ \\
\hline $\begin{array}{l}\text { CT2 - A teoria e a } \\
\text { práxis no contexto da } \\
\text { reorientação da formação e } \\
\text { do modelo de atenção }\end{array}$ & $\begin{array}{l}\checkmark \quad \text { O Pró e Pet-Saúde estimulam a "ação- } \\
\text { reflexão-ação", problematizando a práxis do serviço. } \\
\checkmark \quad \text { O trabalho pode ser fonte de saberes para } \\
\text { os estudantes. } \\
\checkmark \quad \text { Possibilidade de progredir na direção de } \\
\text { um novo modelo de atenção. }\end{array}$ \\
\hline $\begin{array}{l}\text { CT3 - Analogias entre } \\
\text { os mundos do trabalho e do } \\
\text { ensino }\end{array}$ & $\begin{array}{l}\text { É necessário tempo para que os atores } \\
\text { envolvidos compreendam a responsabilidade do serviço } \\
\text { pela ordenação da formação. } \\
\text { As dificuldades ficam por conta das devolutivas } \\
\text { da IES ao serviço. } \\
\text { Os projetos nem sempre atendem as demandas do } \\
\text { ensino e/ou do serviço. }\end{array}$ \\
\hline
\end{tabular}

Fonte: Elaborado pelas autoras, 2017. 


\section{DISCUSSÃO}

O número significativo de cirurgiões dentistas ocorre pelo grande incentivo por parte dos gestores da saúde em Chapecó no envolvimento dessa categoria profissional, tanto nas questões relacionadas à $\mathrm{AB}$, quanto nos processos de reorientação da formação. $\mathrm{Da}$ mesma forma, a participação de profissionais da medicina nos grupos indica abertura e interesse dessa categoria em relação à esses processos. Nessa perspectiva, a IES compreende como relevante o desafio de criar oportunidades para o trabalho em equipe na formação de profissionais, na direção da integralidade do cuidado, o que requer o envolvimento efetivo dos diferentes trabalhadores. Acredita-se na necessidade da inserção do graduando em seu contexto profissional, durante o processo de formação, considerando a diversificação dos cenários de aprendizagem e o cuidado com a formação ético-humanista (BRASIL, 2007a; FINKLER; CAETANO; RAMOS, 2011).

\section{Mundos entrelaçados: participação dos profissionais nas atividades acadêmicas e dos estudantes no cotidiano da equipe de saúde}

Em relação ao envolvimento dos atores na organização dos mundos do trabalho e do ensino, os profissionais referem sua receptividade para com os estudantes na Unidade Básica de Saúde (UBS). Segundo esses, participar de iniciativas na universidade promove maior interesse e potencial para contribuir em relação as atividades integradas de formação. No entanto, os entrevistados mencionam que, por vezes, ficam alheios à passagem dos estudantes pelo serviço, absorvidos por suas tarefas. Além disso, nem sempre se sentem estimulados a acompanhar as atividades desenvolvidas pelos estudantes pois, para o gestor, essa inserção seria uma demanda exclusiva da IES, não sendo vista como parte do processo de aprimoramento do serviço e da educação permanente dos profissionais:

Quando comunicada a gerência, é possível [aos profissionais] acompanhar acadêmicos nas atividades [...]. Normalmente, quem recebe orientação [sobre o que será realizado pelos estudantes] é a enfermeira coordenadora (Profissional 3).

$\mathrm{Na}$ ótica dos entrevistados, a integração ensino-serviço ocorre com a participação dos profissionais de saúde nas atividades acadêmicas, de ensino, pesquisa e/ou extensão 
(dentre as quais, preceptorias do PET-Saúde). O fato de a participação ser ou não espontânea, pode influenciar no grau de envolvimento dos atores.

A integração é feita pela participação de alguns profissionais da saúde, alguns voluntariamente, outros não (Profissional 1).

[...] quando não tem [remuneração], é uma coisa a mais para fazer. É difícil convencer os profissionais. (Gestor 4).

$\mathrm{Na}$ Unochapecó, os profissionais da rede têm participado de forma mais ativa em duas iniciativas vinculadas ao Pró-Saúde: como tutores no projeto VIM e como preceptores nos grupos do PET-Saúde. No primeiro, aderem por interesse, sendo liberados pelo gestor em seu horário de trabalho. Já no caso dos grupos do PET-Saúde, os profissionais se inscrevem em editais específicos e são selecionados pela Sesau. De 2011 a 2013, por iniciativa do grupo gestor da Sesau, profissionais preceptores do PET-Saúde foram mobilizados a assumir tutoria no VIM como contrapartida de sua inserção como bolsista.

Ambas as estratégias implicam no envolvimento do profissional de saúde com o meio acadêmico, reconhecendo e valorizando seu papel, com respaldo do professor/tutor, procedente da universidade (BRASIL, 2007a). Todavia, na ótica do gestor, muitos profissionais não se envolvem com ações de integração com a universidade sem incentivo financeiro, como é o caso das bolsas do PET-Saúde.

Quando veio o PET, foi um caos, porque ninguém queria trabalhar nos projetos do Pró se não fossem preceptores do PET, se não recebessem [bolsa]. [...] Eu me lembro das coordenadoras, dizendo: "Por que eu vou ter que acolher, se quem está recebendo é ela que tem [bolsa do] PET?" Isso criou na rede um atrito [...] (Gestor 3).

Em relação ao VIM, [...] tem e cada vez mais vai ter essa dificuldade de os profissionais aderirem, porque não tem remuneração. [...] E quando eles fazem [a tutoria do VIM] por que é [bolsista] do PET, mas fazem contra a vontade, se percebe uma revolta [...] (Gestor 4).

A opinião dos gestores reforça a ideia de que a inserção do ensino no serviço precisa garantir certos ganhos que beneficiem os envolvidos, para além das oportunidades de educação permanente por meio do compartilhamento de saberes e na resolução de problemas a partir do cotidiano do trabalho (BRASIL, 2007b). Nessa direção, se evidenciam 
cobranças relativas à determinadas contrapartidas por parte da universidade, em troca da "cedência" dos espaços de prática e do envolvimento dos profissionais no processo de formação.

[...] quantas vagas de graduação vocês vão dar para os nossos profissionais? [...] Desde 2008 a gente está conversando para qualificar os nossos profissionais, abrindo vagas nessas instituições de ensino para quem é ensino médio. $O$ que custava? (Gestor 2).

Os nossos profissionais que são os preceptores [do PET-Saúde] [...] eles não têm carteirinha e não podem pegar livros na universidade! [...] Mas [...], eles estão recebendo alunos! São eles que estão lá com os alunos! (Gestor 4)

Outra reivindicação dos gestores em relação à integração, é que a IES deveria interferir no serviço a partir de evidências, a partir de produtos gerados por meio da pesquisa e da extensão.

[...] o papel da instituição de ensino ou dessa interação ensino-serviço? Seria esse olhar da universidade, esse olhar baseado em evidências, vindo para dentro de um centro de saúde, onde o dia a dia é "pauleira" e dizendo: "Para aí! Você está agindo assim, mas se você agisse assim"? (Gestor 3)

Contudo algumas falam evidenciam o reconhecimento da participação dos estudantes da saúde nas ações cotidianas da equipe como um fator que contribui para a integração ensino-serviço, na medida em que favorece a educação permanente dos profissionais:

0 acadêmico muda e interfere na realidade local; traz conceitos e posturas que fazem com que a equipe pense, cresça nos aspectos científicos. Os profissionais interagem [com os estudantes], mostrando a realidade do dia a dia (Profissional 2).

Quando existe acadêmico dentro do serviço, os profissionais procuram se atualizar, procuram fazer as coisas de uma forma diferente, se reciclar (Gestor 5).

Sob a ótica da educação permanente, a integração ensino-serviço-comunidade se constitui como estratégia de transformação da aprendizagem em momentos significativos, incentivadores de mudanças no trabalho e no ensino, tornando-os cenários de atuações 
críticas, reflexivas, propositivas, compromissadas e tecnicamente competentes (TOMBINI, 2010). Nessa direção, o resultado esperado é a democratização dos espaços, o desenvolvimento da capacidade de aprender e de ensinar entre os atores, a busca de soluções criativas para os problemas do processo laboral, melhoria da qualidade do cuidado, interferindo positivamente nas condições de saúde da comunidade (BRASIL, 2007b).

\section{A teoria e a práxis no contexto da reorientação da formação e do modelo de atenção}

Para que a inserção do estudante no cotidiano do trabalho e na vida das comunidades seja produtiva e coerente, é imprescindível construir parcerias entre universidades e serviços de saúde (VENDRUSCOLO et al, 2016). Os serviços são cenários importantes para a formação voltada para o SUS, sobretudo ao contribuírem para as mudanças na lógica da atenção integral aos cidadãos. Como uma das ações estruturantes da proposta da Unochapecó, o VIM inclui exercícios de observação nos serviços de saúde e seus territórios, desde os primeiros períodos da graduação, estimulando a "ação-reflexão-ação", na perspectiva de problematizar e qualificar a práxis do serviço:

Através dos estágios de observação, já nos primeiros períodos da graduação, o acadêmico entra em contato direto com os profissionais da saúde, em seu fazer diário, e com a população que utiliza destes serviços (Profissional 7).

[...] começa com a vivência [VIM]: [...] a rede participa de atividades na Unochapecó, após, os estudantes vão às UBS, vivenciar a realidade, e retornam ao grupo para relatos [e] de experiências vividas (Profissional 5).

A partir das ideias de Freire, a integração ensino-serviço-comunidade possibilita ultrapassar o âmbito da apreensão da realidade para uma esfera crítica da tomada de consciência, por meio da aproximação entre a teoria e a prática. É por meio da interação com a realidade que podem ser desenvolvidas ações de intervenção para sua transformação e é com vistas ao desenvolvimento da capacidade de "aprender fazendo" que essa interação se materializa (FREIRE, 2005).

[...] é essencial, para que haja uma maior aproximação do cenário real e do exercício diário de relações multi e interdisciplinares. A possibilidade de 
concretizar as práticas, de participar da construção de novos modelos, de intervir nos modelos atuais e de permitir conhecer os usuários e suas demandas reais (Profissional 7).

o fato de o Pró e o PET estarem dentro do serviço, faz com que a gente também recorde para o que viemos: para dentro do SUS! (Gestor 3).

$\mathrm{Na}$ lógica da integração ensino-serviço, a preceptoria configura-se como um elemento pedagógico fundamental, ao conceber o trabalho como fonte de saberes e de experiência (FINKLER; CAETANO; RAMOS, 2011). Os participantes salientam a diferença entre a integração do estudante que provém de uma IES com Pró e/ou PET-Saúde com a equipe:

A gente percebe uma diferença entre os acadêmicos que vêm de uma instituição que tem uma proximidade maior na construção de algumas práticas. Por exemplo, citando o Pró e PET, em todos os projetos existe uma interação maior do que aquelas instituições que jogam o acadêmico lá; a equipe tem que receber por que tem que receber, não existe um preparo para isso. (Gestor 2)

Acredita-se que as iniciativas que incentivam a reorganização dos sistemas de saúde, mediante a formação e o trabalho dos profissionais, vêm sendo decisivamente impactadas pelas pressões para a reforma da universidade e pelo processo de descentralização político-administrativa do Estado. Os participantes destacaram a potência, fomentada pelas ações estruturantes, de avançar na direção de um novo modelo de atenção, de modo a enfatizar questões culturais, vínculo, humanização e integralidade (ALBUQUERQUE, 2008; VENDRUSCOLO et al, 2016).

\section{Analogias entre os mundos do trabalho e do ensino}

Experiências têm mostrado que a integração ensino-serviço-comunidade fortalece os interessados em transformações na formação e na atuação dos serviços. Nas décadas de 1970 e 1980, a integração docente-assistencial (IDA) inova como estratégia de articulação entre os cursos da área da saúde, tendo contribuído significativamente para a construção do SUS. Contudo, por ser uma experiência que permaneceu isolada na universidade e por estabelecer relações verticais com os serviços, seu impacto na formação profissional foi limitado (FEUERWERKER, 2002; FINKLER; CAETANO; RAMOS, 2011). 
Pode-se perceber que, apesar da receptividade da Sesau à academia, persistem problemas na relação entre trabalho e ensino, relacionados as estratégias de reorientação da formação. As falas refletem inquietação no que tange: ao tempo necessário à compreensão por parte dos atores envolvidos; o conflito entre a responsabilidade do serviço pela ordenação da formação ou da IES pela organização das atividades estudantis de acordo com o processo ensino-aprendizagem; as ações descoladas das necessidades do serviço; e as queixas dos profissionais em relação à presença dos estudantes:

É uma relação delicada. Em alguns momentos, existe uma certa tensão entre as instituições. Entretanto, acredito que a tensão e a negociação fazem parte do processo de criação coletiva [...] (Profissional 4).

[...] tem que existir uma organização, as coisas não podem ser do jeito que uma ou outra universidade quer [...] têm que ser de acordo com aquilo que o serviço pode e precisa ofertar. Não pode ser assim: "eu vou lá para dentro e vou fazer dessa forma" (Gestor 3).

Têm projetos que vem goela abaixo, chegam lá e dizem: "tem que fazer essa pesquisa", [independente se] a secretaria quer ou não quer (Gestor 2).

Apesar de os participantes da pesquisa não manifestarem insatisfação com a presença dos estudantes ou mesmo com as propostas de integração, os gestores salientaram insatisfações e certo sofrimento por parte dos trabalhadores:

[...] a gente percebe conflitos, por que alguns profissionais querem [acadêmicos] e outros profissionais não querem. Isso acaba gerando conflitos dentro das equipes (Gestor 4).

O que a gente tem percebido é que algumas equipes têm adoecido. Quando a gente vai conversar com elas, elas colocam como angústia: "Meu Deus! Não aguento mais tantos alunos!". (Gestor 3).

Outra reivindicação dos gestores é relacionada à devolutiva das informações produzidas pela IES por meio das atividades de ensino, pesquisa e extensão. Entre os gestores fica evidente que não há muita apropriação sobre o que a IES planeja, desenvolve e produz de conhecimentos. Apesar de dois desses referirem ter acompanhado momentos em que a IES envolveu profissionais e gestores dos serviços nestes processos, para a maioria: 
[...] nós da gestão não temos muito contato com o processo pedagógico. A gente se preocupa mais em tentar mediar os conflitos. (Gestor 4)

Existe uma distância em relação ao PP [Projeto Pedagógico], de como ele é organizado de uma forma geral. [...] A gente recebe [os estudantes], sabe que eles vem para cá, que têm um preceptor e um professor orientador. Mas, como que eles são preparados para chegar aqui e como funciona metodologicamente esse processo ensino-aprendizagem do aluno no cenário de prática, a gente não sabe. (Gestor 2).

Transformar a formação profissional implica em mudanças, não somente de concepções e práticas, mas nas relações de poder entre IES, serviços de saúde e no âmbito das políticas. $O$ alicerce dessas propostas é a democratização que se inicia com a construção de espaços de poder compartilhados. Isso pressupõe articulação estratégica de representantes de diferentes segmentos, com poder e conhecimento suficientes para permitir a reflexão crítica, a criação de canais de comunicação, a discussão e deliberação coletiva, potencializando suas ações (FEUERWERKER, 2002).

Contudo, a institucionalização de dispositivos de gestão compartilhada, que criam possibilidades para que sejam reconhecidos interesses comuns e abertos diálogos coletivos, também podem gerar divergências e posições conflituosas (VENDRUSCOLO et al, 2016). Isso requer vontade politica dos atores envolvidos para reconhecer e fazer a gestão dos conflitos, de forma que as diferenças possam ser ressignificadas, gerando transformações efetivas.

No contexto da parceria entre a Unochapecó e a Sesau, diálogos são estabelecidos na Comissão Coordenadora Local, instância de gestão e coordenação das ações interministeriais. Tal espaço oportuniza aos diferentes segmentos representados (ensino, serviço, controle social e gestão) comunicar-se e agir diante das situações mais diversas.

As considerações demonstram envolvimento positivo dos profissionais e gestores com as propostas de integração, quer seja pelos projetos desenvolvidos, quer seja pelos benefícios materiais ou de educação permanente:

Eu acho que estamos todos juntos. Não pode ter essa situação se está do lado de um ou de um lado do outro! [...] Tem que sentar, conversar [...] (Gestor 5). 
Acho que a gente teve conquistas muito grandes! Por exemplo, as salas de educação permanente, dentro dos centros de saúde foram conquistas importantes do Pró. (Gestor 3).

Considera-se que os objetivos de fortalecimento da $A B$ e de consolidação do SUS são comuns ao serviço, ao ensino e a comunidade. Neste sentido, o caso estudado, à exemplo de outras experiências no âmbito da reorientação da formação em saúde no Brasil (FINKLER; CAETANO; RAMOS, 2011; SCHIMIDT, 2008; VENDRUSCOLO et al., 2016), mostra que a interdependência entre prática e teoria, e que a integração das instituições, por meio do envolvimento efetivo dos atores, é condição fundamental para a adequação do processo de formação às necessidades do SUS.

\section{CONSIDERAÇÕES FINAIS}

A integração ensino-serviço-comunidade foi, em grande medida, sinalizada no pensamento e no trabalho dos profissionais participantes da pesquisa, os quais se compreendem (co)responsáveis pelo processo de reorientação da formação, na direção do fortalecimento da $\mathrm{AB}$ e da consolidação do SUS. Todavia, a participação efetiva dos profissionais da saúde nas ações e demandas da IES exige reconhecer essa integração como oportunidade de reorientação de sua própria formação, por meio da educação permanente, que contribui para a transformação do processo de trabalho. Nessa perspectiva, questões como sobrecarga de trabalho, expectativa de ganhos financeiros, divergências entre necessidades do serviço e do ensino são apontadas como fatores de resistência ao processo de integração.

Da mesma forma, apesar de se sentirem corresponsáveis no processo de formação, os gestores destacam problemas e conflitos referidos pelos profissionais. Por outro lado, evidencia-se a dificuldade de os gestores acompanharem o planejamento e as devolutivas promovidas pela universidade, fundamentais para a integração ensino-serviço-comunidade e para o exercício do papel de ordenador da formação conferido ao SUS.

A incorporação de mecanismos que favorecem a aproximação entre os atores do ensino, do serviço e da comunidade na saúde permanece um desafio diante da reorientação 
do modelo assistencial. Instâncias de diálogo entre gestores, trabalhadores, docentes e usuários favorecem seu enfrentamento, viabilizando processos de reorientação da formação profissional em saúde, fundamentais para consolidar o SUS.

\section{REFERÊNCIAS}

ALBUQUERQUE, V.S; GOMES, A.P.; REZENDE, C.H.A.; SAMPAIO, M.X.; DIAS, O.V.; LUGARINHO, R.M. A integração ensinoserviço no contexto dos processos de mudança na formação superior dos profissionais da saúde. RBEM, v.32, n.3, p.356-62, 2008. Disponível em: http://www.scielo.br/pdf/rbem/v32n3/v32n3a10.pdf. Acesso em: 17ago. 2017.

BARDIN, L. Análise de conteúdo. São Paulo: Edições 70, 2011.

BRASIL. Resolução CNE/CES nº1133 de 2001. Diretrizes Curriculares Nacionais dos Cursos de Graduação em Enfermagem, Medicina e Nutrição. Diário Oficial da União, Brasília, 2001. Seção 1E, p. 131. Disponível em: http://portal.mec.gov.br/dmdocuments/ces1133.pdf. Acesso em: 28 Ago. 2017.

BRASIL. Ministério da Saúde. Ministério da Educação. Programa Nacional de Reorientação Profissional em Saúde Pró-Saúde: objetivos, implementação e desenvolvimento potencial. Brasília, 2007a. Disponível em: http://prosaude.org/rel/pro_saude1.pdf. Acesso em: 17ago. 2017.

BRASIL. Ministério da Saúde. Portaria GM/MS no 1.996/07, de 20 de agosto de 2007. Dispõe sobre as diretrizes para a implementação da Política Nacional de Educação Permanente em Saúde. Brasília, 2007b. Disponível em: http://www.saude.pb.gov.br/site/geab/portaria2007.pdf. Acesso em: 28 ago. 2017.

BRASIL. Ministério da Saúde. Ministério da Educação. Lei no 11.788, de 25 de setembro de 2008. Dispõe sobre o estágio de estudantes. Disponível em: http://www.cvm.gov.br/export/sites/cvm/menu/acesso_informacao/servidores/estagios/3LEGISLACAO-DE-ESTAGIO.pdf. Acesso em: 27 ago. 2017

BRASIL. Ministério da Saúde. Ministério da Educação. Programa de Educação pelo Trabalho para a Saúde. Brasília, 2010. Disponível em: http://portalsaude.saude.gov.br/index.php/o-ministerio/principal/secretarias/sgtes/sgtes-gestao-daeducacao/pet-saude. Acesso em: 28 mar. 2017.

FEUERWERKER, L. Além do discurso de mudança na educação médica: processos e resultados. São Paulo: Hucitec, 2002.

FINKLER, M.; CAETANO, J. C.; RAMOS, F. R. S. Integração "ensino-serviço" no processo de mudança na formação profissional em Odontologia. Interface comun. Saúde educ, v.15, n.39, p.1053-67, 2011. Disponível em: http://www.scielo.br/pdf/icse/v15n39/aop2011.pdf. Acesso em: 02 set. 2017.

FREIRE, P. Conscientização: teoria e prática da libertação: uma introdução ao pensamento de Paulo Freire. São Paulo: Centauro, 2001, 116p.

FREIRE, P. Pedagogia do oprimido. 59a ed. Rio de Janeiro: Paz e Terra; 2005.

SCHIMIDT, S. O processo de formação dos cursos de graduação em enfermagem, medicina e odontologia nos serviços de atenção básica. 2008. 181 f. Tese (Doutorado) Florianópolis (SC): UFSC/PEN, 2008.

TOMBINI, L.H.T. Educação permanente e integração ensino-serviço na perspectiva dos enfermeiros do serviço. Dissertação (Mestrado em Enfermagem) Florianópolis (SC): UFSC/PEN, 2010.

VENDRUSCOLO, C.; FERRAZ, F. ; PRADO, M. L.; KLEBA, M.E.; REIBNITZ, K.S. Teaching-service integration and its interface in the context of reorienting health education. Interface (Botucatu. Impresso), v. 20, p. 1015-1025, 2016. Disponível em: http://www.scielo.br/pdf/icse/v20n59/en_1807-5762-icse-1807-576220150768.pdf. Acesso em: 02 set. 2017.

VENDRUSCOLO, C.; PRADO, M. L. ; KLEBA, M.E. Integração Ensino-Serviço no âmbito do Programa Nacional de Reorientação da Formação Profissional em Saúde. Ciência \& Saúde Coletiva, v. 21, p. 2949-2960, 2016. Disponível em: http://www.scielo.br/pdf/csc/v21n9/1413-8123-csc-21-09-2949.pdf. Acesso em 02 set. 2017.

YIN, R. K. Estudo de caso: planejamento e métodos. 4a ed. Porto Alegre: Bookman; 2010. 